\title{
Effects of Age, Sex, and Race on the Safety and Pharmacokinetics of Single and Multiple Doses of Azilsartan Medoxomil in Healthy Subjects
}

\author{
Robert E. Harrell $^{1} \cdot$ Aziz Karim $^{2} \cdot$ Wencan Zhang $^{3} \cdot$ Caroline Dudkowski $^{3}$
}

Published online: 27 October 2015

(C) Springer International Publishing Switzerland 2015

\begin{abstract}
Background and Objective Azilsartan medoxomil (AZL$\mathrm{M})$ is an angiotensin II receptor blocker approved to treat hypertension. After oral dosing, AZL-M is quickly hydrolyzed to azilsartan (AZL). The aims of this study were to assess the effects of age, sex, and race on the pharmacokinetics of AZL$\mathrm{M}$ in healthy subjects, as well as safety and tolerability.

Methods Sixty-one healthy adults were enrolled in this phase I, single-blind, randomized placebo-controlled study (placebo control was for assessment of safety/tolerability only). Subjects were stratified by age (18-45 vs. 65-85 years), sex, and race (black vs. white) and given oral AZL-M $60 \mathrm{mg}(3 \times 20 \mathrm{mg}$ capsules $)$ or placebo as a single dose (Day 1) and consecutive daily doses (Days 4-8) (6:2 ratio for AZL-M:placebo per group). Pharmacokinetics were evaluated (AZL-M patients only) on Days 1-3 and 8-9 and safety/tolerability was monitored.

Results Age, sex, and race had no clinically meaningful effect on AZL exposures after single or multiple dosing. Pharmacokinetic parameters remained similar between Days 1 and 8 for each age, sex, and race subgroup. The frequency of adverse events was similar for AZL-M (32\%) and placebo (29\%). No discontinuations or serious adverse events occurred.

Conclusions Based on these pharmacokinetic and safety/tolerability findings, no AZL-M dose adjustments are required based on age, sex, or race (black/white).
\end{abstract}

\section{Robert E. Harrell}

1 Arkansas Research Medical Testing, 22 Rubra Ct, Little Rock, AR 72223, USA

2 AzK Consulting, Skokie, IL, USA

3 Takeda Development Center Americas, Deerfield, IL, USA

\section{Key Points}

Age, sex, and race appear to have no clinically significant impact on the pharmacokinetics of azilsartan.

No adjustments in azilsartan medoxomil dosage are required on the basis of age, sex, or race.

\section{Introduction}

The use of drugs acting on the renin-angiotensin system (RAS), principally angiotensin converting enzyme inhibitors and angiotensin II receptor blockers (ARBs), has become established as an important component in the contemporary management of patients with hypertension [1]. The latest JNC8 Guidelines recommend RAS inhibitors (alone or in combination with other drugs) as the firstline therapy treatment for patients with chronic kidney disease (CKD), with or without diabetes mellitus and for all ages and races [1]. These agents are also one of the recommended first-line agents for those without CKD, especially in non-black patients [1]. As second-line agents, RAS inhibitors are one of the recommended components of combination therapy available to patients irrespective of age, sex, or race [1].

Azilsartan medoxomil (AZL-M) is a potent ARB approved for the treatment of hypertension at a dose of 20-80 mg once daily, alone or in combination with other antihypertensive agents [2-5]. After oral dosing, AZL-M (a pro-drug) is rapidly hydrolyzed during absorption in the gut and/or gut wall to form its active moiety, azilsartan (AZL) $[2,5]$. Unchanged AZL-M is not detected in blood at any 
time. Based on previous pharmacokinetic analyses, peak plasma concentrations of AZL are reached within 1.5-3 h after oral dosing, elimination half-life is approximately $11 \mathrm{~h}$, and renal clearance is approximately $2.3 \mathrm{~mL} / \mathrm{min}[2$, 5]. Assuming total conversion to AZL, the apparent oral clearance of AZL-M after non-compartmental analysis is approximately $1.5 \mathrm{~L} / \mathrm{h}$ [6]. Systemic exposure of AZL with the capsule formulation of AZL-M (as used in the initial clinical development phase and in the current study) was shown to be higher when the capsules were administered with food. This food-effect response was minimized with the commercial tablet formulation.

Both renal and hepatic metabolism contribute to the elimination of AZL, although neither mild-to-severe renal impairment nor mild-to-moderate hepatic impairment has any clinically relevant impact on AZL exposure $[2,5,7,8]$. Systemic exposure of the main metabolite of AZL (M-II; formed by $O$-dealkylation via the cytochrome P450 2C9 isoform) is also unchanged with hepatic impairment, but is increased in patients with renal impairment; however, this increase has no clinical relevance because M-II is not pharmacologically active $[2,5,7,8]$. Similarly, the minor metabolite M-I (formed by decarboxylation) is not pharmacologically relevant $[2,5]$.

The possibility of alterations in AZL pharmacokinetics in the elderly is a particularly important consideration because of the potential for age-related impairments in physiologic processes and the resultant decline in drug metabolism and excretion $[9,10]$. In addition, potential pharmacokinetic differences according to sex and/or race remain a key consideration with all pharmacologic agents. If clinically relevant differences in drug exposure are present, dose adjustments or altered dosing schedules may be required in specific patient populations to maximize efficacy or minimize the risk of adverse effects.

Because hypertension can affect any individual, regardless of age, sex, or race, it is important to establish the pharmacokinetic and tolerability/safety profile of AZL within these populations. The current study evaluated the possible effects of age, sex, and race on AZL pharmacokinetics and AZL safety/tolerability after single and multiple (five consecutive) daily doses of AZL-M $60 \mathrm{mg}$ in healthy adult subjects.

\section{Methods}

This was a phase I, single-center, single-blind, randomized, parallel-group, single- and multiple-dose, placebocontrolled study. The placebo-controlled component was for the assessment of safety only. The study was performed at Arkansas Research Medical Testing, Little Rock, AR, USA, where it was approved by the
Institutional Review Board for Arkansas Research Medical Testing, Little Rock, AR, USA and undertaken in accordance with the Declaration of Helsinki. Written informed consent was obtained directly from all participants prior to entry into the study and prior to any study procedures.

\subsection{Study Participants}

The study population consisted of 61 healthy, non-hypertensive black or white men or women aged 18-45 years ("young") or 65-85 years ("elderly"), with a body mass index (BMI) of $18-33 \mathrm{~kg} / \mathrm{m}^{2}$ and minimum body weight of $50 \mathrm{~kg}$. Exclusion criteria included: (1) history of drug/alcohol abuse; (2) history or clinical manifestations of significant metabolic, hematologic, pulmonary, cardiovascular, gastrointestinal, neurologic, hepatic, renal, urologic, immunologic, or psychiatric disorders (unless approved on a case-by-case basis); (3) abdominal surgery or thoracic or nonperipheral vascular surgery in the previous 6 months; (4) systolic blood pressure $>140$ or $<110 \mathrm{mmHg}$, or a diastolic blood pressure $>90$ or $<70 \mathrm{mmHg}$; (5) history or presence of an abnormal, clinically significant 12-lead ECG result; (6) pregnancy/lactation; (7) hemoglobin $<12 \mathrm{~g} / \mathrm{dL}$; (8) alanine transaminase level $>1.5 \times$ upper limit of normal, active liver disease, or jaundice; (9) blood donation or acute blood loss $>500 \mathrm{~mL}$ in the previous 30 days; (10) history of cancer (except basal cell or stage 1 squamous cell carcinoma of the skin) that had not been in remission for the previous 5 years; and (11) tobacco or nicotine product use in the previous 30 days.

The following medications/food products were prohibited for the duration of the subject's participation in the study and for varying time periods prior to study entry: (1) prescription medications (except those approved on a caseby-case basis) and neutraceuticals (28 days prior to study entry); (2) over-the-counter medications (except those approved on a case-by-case basis) and vitamin supplements (14 days prior to study entry); and (3) alcohol- and caffeine-containing products, foods, or beverages containing Seville (sour) orange- and grapefruit-containing products (72 h prior to study entry).

Subjects were stratified according to age (young [Y]or elderly $[\mathrm{E}]$ ), sex (male $[\mathrm{M}]$ or female $[\mathrm{F}]$ ), and race (black [B] or white [W]) into eight treatment groups (YFB, EFB, YMB, EMB, YFW, EFW, YMW, EMW). Each group consisted of eight subjects-six randomized to receive AZL-M $60 \mathrm{mg}$ and two randomized to receive placebo. Because of the difficulty in enrollments, the EFB group was an exception $(n=5)$, with no subjects receiving placebo. Following screening (Days -28 to -2 ), subjects were admitted to the clinic on Day -1 and confined to the clinic for a total of 9 nights until Day 9. 


\subsection{Treatment Allocation}

Randomly allocated study treatment (AZL-M $60 \mathrm{mg}$ [3 $\times 20 \mathrm{mg}$ oral capsules] or matching placebo) was administered once per day in the morning as a single dose on Day 1 and consecutive single doses on Days 4-8, inclusive. Treatment was administered immediately following consumption of a standardized breakfast containing approximately $600-800 \mathrm{kcal}$ and approximately $30 \%$ fat. The 60-mg dose of the AZL-M capsule was chosen for the current study as it provided a significant decrease in blood pressure, while being safe and well tolerated, in early clinical studies where AZL-M was administered without regard to meals (US FDA, 2011).

\subsection{Bioanalytical Methods}

Blood samples were obtained at time points up to $72 \mathrm{~h}$ post-dose after the single dose on Day 1 , before dosing on Days 6,7 , and 8 , and up to $24 \mathrm{~h}$ post-dose after the last dose on Day 8 to determine the concentrations of AZL. All blood samples were collected into chilled 6-mL tubes containing potassium ethylene diamine tetra-acetic acid and centrifuged, and the plasma was then removed. Samples were stored at approximately $-70{ }^{\circ} \mathrm{C}$ or lower.

The AZL concentrations in plasma samples were determined using a validated liquid chromatography-tandem mass spectrometry assay at Covance Laboratories, Madison, WI, USA. The samples were acidified and the internal standard was added. AZL and the internal standard were then extracted using OASIS ${ }^{\circledR}$ HLB, 96-well solidphase extraction plates (Waters, Milford, MA, USA). Liquid chromatography separation was obtained using an Xterra ${ }^{\circledR}$ RP18 column (Waters; $250 \times 2.1 \mathrm{~mm}, 5 \mu \mathrm{m}$ ). The mobile phase consisted of an acetonitrile:water:acetic acid gradient (60:40:0.05, v:v:v)/acetonitrile and was pumped through the column at a flow rate of $0.2 \mathrm{~mL} / \mathrm{min}$. For detection, an API 3000 mass spectrometer (AB Sciex, Framingham, MA, USA) with positive ion electrospray in multiple-reaction monitoring mode was used. The LC-MS/ MS assay range and precision for the quality control samples in this study were $1.00-2500 \mathrm{ng} / \mathrm{mL}$ and $3.6-8.0 \%$, respectively.

\subsection{Pharmacokinetic and Safety Assessments}

Pharmacokinetic variables derived from AZL concentrations in plasma were calculated, including $\mathrm{AUC}_{0-\infty}$ (area under the plasma concentration-time curve from time $0 \mathrm{~h}$ to infinity, single dose only, Day 1); $\mathrm{AUC}_{0-24}$ (area under the plasma concentration-time curve from time 0 to $24 \mathrm{~h}$ post dose [one dose interval], after multiple doses only, Day 8); $C_{\max }$ (maximum observed drug concentration in plasma); $t_{\max }$ (time to reach $C_{\max }$ ); and $t_{1 / 2}$ (terminal halflife, single dose only). Pre-dose trough concentration $\left(C_{\min }\right)$ was also assessed on Days 6-8. Pharmacokinetic parameters were derived using noncompartmental methods with WinNonlin ${ }^{\circledR}$ Professional Version 4.10 (Pharsight Corp., Mountain View, CA, USA).

Placebo subjects were assessed for safety/tolerability only. Safety and tolerability parameters included adverse events, clinical laboratory tests (hematology and serum chemistry), vital signs, 12-lead electrocardiogram, and physical examination findings.

\subsection{Statistical Analysis}

All data analyses were performed using Statistical Analysis System $\left(\mathrm{SAS}^{\circledR}\right.$, Version 9.1, SAS Institute, Cary, NC, USA). An alpha of 0.05 was used for any hypothesis tests performed. Descriptive statistics were used to summarize the pharmacokinetic parameters according to age, sex, and race. An analysis of covariance (ANCOVA) was performed (with fixed effects for age, sex, and race, and body weight as a covariate) on the natural logarithms of the pharmacokinetic variables $\mathrm{AUC}_{0-\infty}, \mathrm{AUC}_{0-24}$, and $C_{\max }$. Point estimates for comparing groups (elderly vs. young, female vs. male, white vs. black) were calculated and presented as ratios; these were obtained by exponentiating estimates of the difference in between-group least-squares means on the log-transformed parameters obtained within the framework of the ANCOVA model. Confidence intervals (CIs) for these estimates were similarly obtained by exponentiating the endpoints of $90 \%$ CIs for the between-group differences of the log-transformed parameters.

To assess linear kinetics of AZL, an analysis of variance (ANOVA) with fixed effects for age, race, sex, day, interaction terms age-by-race, age-by-sex, race-by-sex, and age-by-race-by-sex, and subject nested within age-by-raceby-sex as random effect was performed on the natural logarithms of $\mathrm{AUC}_{0-\infty}$ for the single dose (Day 1) and $\mathrm{AUC}_{0-24}$ for the multiple dose (Day 8) for AZL. A $90 \% \mathrm{CI}$ for the ratio of the least squares means of the multiple-dose $\mathrm{AUC}_{0-24}$ relative to the single-dose $\mathrm{AUC}_{0-\infty}$ was derived within the framework of ANOVA.

The natural logarithms of pre-dose concentrations on Days 6,7 , and 8 were analyzed to assess the achievement of steady state. An ANOVA with the same interaction terms listed above was performed. Within the model, a pairwise $t$ test was used to assess the achievement of steady state by comparing the pre-dose concentration between study days. 


\section{Results}

\subsection{Subject Characteristics}

Demographic and baseline characteristics for the subject population are summarized in Table 1. Mean age was approximately 31 years for "young" subjects and 70 years for "elderly" subjects, and mean BMI was approximately $27 \mathrm{~kg} /$ $\mathrm{m}^{2}$. The AZL-M and placebo groups had similar demographic characteristics. All subjects completed the study.

\subsection{Azilsartan Pharmacokinetics}

The AZL concentration-time profiles after a single dose (Day 1) and after multiple dosing (Day 8) of AZL-M according to age, sex, and race are shown in Figs. 1 and 2, and pharmacokinetic parameter estimates are shown in Table 2. Elderly subjects had a higher total AZL exposure (AUC) after both a single dose (ratio 1.36, $90 \%$ CI 1.05, 1.77) and after multiple dosing (ratio $1.26,90 \%$ CI 1.01, 1.57) compared with young subjects (Table 3; Fig. 2). Elderly subjects also had higher peak AZL exposure $\left(C_{\max }\right)$ after both a single dose (ratio $1.37,90 \%$ CI 1.02, 1.86) and after multiple dosing (ratio $1.15,90 \%$ CI 0.89, 1.49) compared with young subjects (Table 3; Fig. 3). There were no clinically relevant differences for female vs. male subjects or black vs. white subjects in terms of total or peak
AZL exposure after either a single dose or after multiple dosing (Table 3; Figs. 2, 3). No notable differences in time to peak exposure $\left(t_{\max }\right)$ were evident according to age, sex, and race (Table 2).

An assessment of pooled data from all subjects who received AZL-M showed no difference in AZL exposure between a single dose $\mathrm{AUC}_{0-\infty}$ (Day 1) and $\mathrm{AUC}_{0-24}$ at steady state after multiple dosing (Day 8) (LS mean 22281 vs. $22141 \mathrm{ng} \cdot \mathrm{h} / \mathrm{mL}$, respectively; $\mathrm{AUC}_{0-\infty}$ Day $1 / \mathrm{AUC}_{0-24}$ Day 8 ratio $0.99,90 \%$ CI $0.93,1.06$ ). Similarly, no notable differences between single-dose (Day 1) and multiple-dose (Day 8) pharmacokinetic parameters were evident according to age, sex, or race (Tables 2,3).

Steady state plasma trough AZL concentrations $\left(C_{\min }\right)$ on Days 6 through 8 differed less than $20 \%$ (213.2, 249.5, and $250.6 \mathrm{ng} / \mathrm{mL}$ for Days 6, 7, and 8, respectively). No statistically significant difference was noted between $C_{\min }$ values on Days 7 and $8(p=0.947)$.

The results of subgroup analyses suggested a higher AZL $C_{\max }$ and AUC (56-57\% higher on Day 8) in elderly women compared with young women, although this was based on relatively small numbers of subjects (11 vs. 12, respectively) and one young black woman had substantially lower $C_{\max }$ and AUC values $(322 \mathrm{ng} / \mathrm{mL}$ and $3059 \mathrm{ng} \cdot \mathrm{h} / \mathrm{mL}$ on Day 8) compared with the rest of the study population. Elderly women also had higher AZL $C_{\max }\left(57 \%\right.$ higher) and $\mathrm{AUC}_{0-24}(35 \%$ higher) compared

Table 1 Demographic and baseline characteristics stratified by age, sex, and race

\begin{tabular}{|c|c|c|c|c|}
\hline Demographic variable & Azilsartan medoxomil & Placebo & Azilsartan medoxomil & Placebo \\
\hline Age & Elderly & & Young & \\
\hline$N$ & 23 & 6 & 24 & 8 \\
\hline Age, years (mean \pm SD) & $68.7(4.8)$ & $73.0(5.8)$ & $31.4(8.6)$ & $30.0(7.0)$ \\
\hline Sex, female/male $(n)$ & $11 / 12$ & $2 / 4$ & $12 / 12$ & $4 / 4$ \\
\hline Race, white/black $(n)$ & $12 / 11$ & $4 / 2$ & $12 / 12$ & $4 / 4$ \\
\hline BMI, $\mathrm{kg} / \mathrm{m}^{2}($ mean $\pm \mathrm{SD})$ & $28.2(3.3)$ & $26.7(3.5)$ & $25.8(3.8)$ & $27.0(4.2)$ \\
\hline Body weight, kg (mean \pm SD) & $81.2(12.6)$ & $81.0(18.9)$ & $75.9(10.4)$ & $81.4(15.5)$ \\
\hline Sex & Female & & Male & \\
\hline$N$ & 23 & 6 & 24 & 8 \\
\hline Age, years (mean \pm SD) & $49.0(19.7)$ & $47.2(21.5)$ & $50.2(20.9)$ & $49.4(25.4)$ \\
\hline Race, white/black $(n)$ & $12 / 11$ & $4 / 2$ & $12 / 12$ & $4 / 4$ \\
\hline BMI, $\mathrm{kg} / \mathrm{m}^{2}($ mean $\pm \mathrm{SD})$ & $27.7(4.1)$ & $26.4(4.5)$ & $26.4(3.3)$ & $27.3(3.4)$ \\
\hline Body weight, kg (mean \pm SD) & $74.5(9.8)$ & $71.5(12.0)$ & $82.4(12.2)$ & $88.6(15.8)$ \\
\hline Race & White & & Black & \\
\hline$N$ & 24 & 8 & 23 & 6 \\
\hline Age, years (mean $\pm \mathrm{SD})$ & $49.1(23.0)$ & $54.5(24.0)$ & $50.2(17.1)$ & $40.3(20.7)$ \\
\hline Sex, female/male $(n)$ & $12 / 12$ & $4 / 4$ & $11 / 12$ & $2 / 4$ \\
\hline BMI, $\mathrm{kg} / \mathrm{m}^{2}($ mean $\pm \mathrm{SD})$ & $27.2(3.5)$ & $27.5(2.2)$ & $26.8(4.0)$ & $26.1(5.4)$ \\
\hline Body weight, kg (mean \pm SD) & $78.8(12.9)$ & $83.7(11.8)$ & $78.2(10.5)$ & $77.9(21.9)$ \\
\hline
\end{tabular}

BMI body mass index, Black Black or African American, Elderly age 65-85 years, Young age 18-45 years, $S D$ standard deviation 
Fig. 1 Azilsartan

concentration-time profiles after a single dose (Day 1) of azilsartan medoxomil according to age (top), sex (middle), and race (bottom). All data are mean \pm standard error of the mean
Azilsartan Exposure by Age: Elderly (65-85 yr) vs Young (18-45 yr)

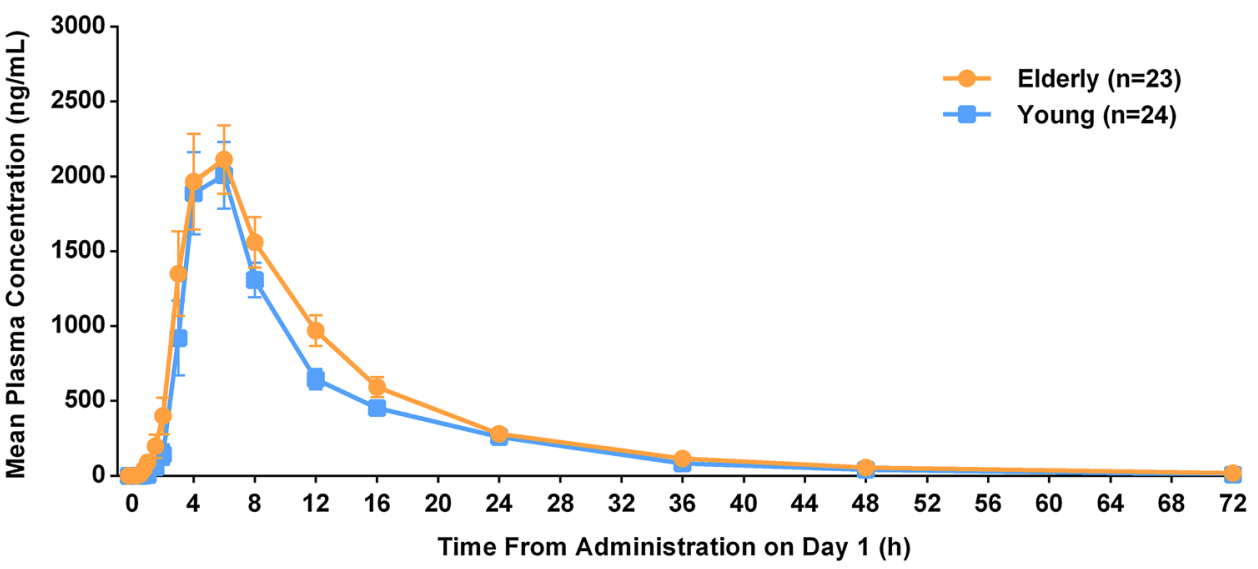

Azilsartan Exposure by Gender: Female vs Male

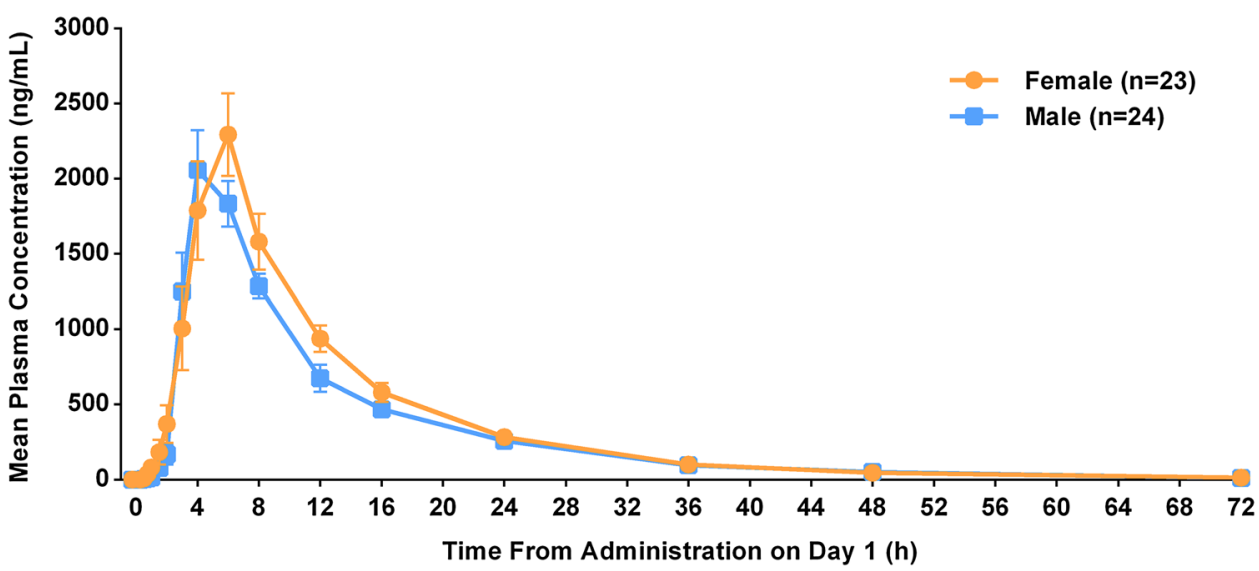

Azilsartan Exposure by Race: White vs Black

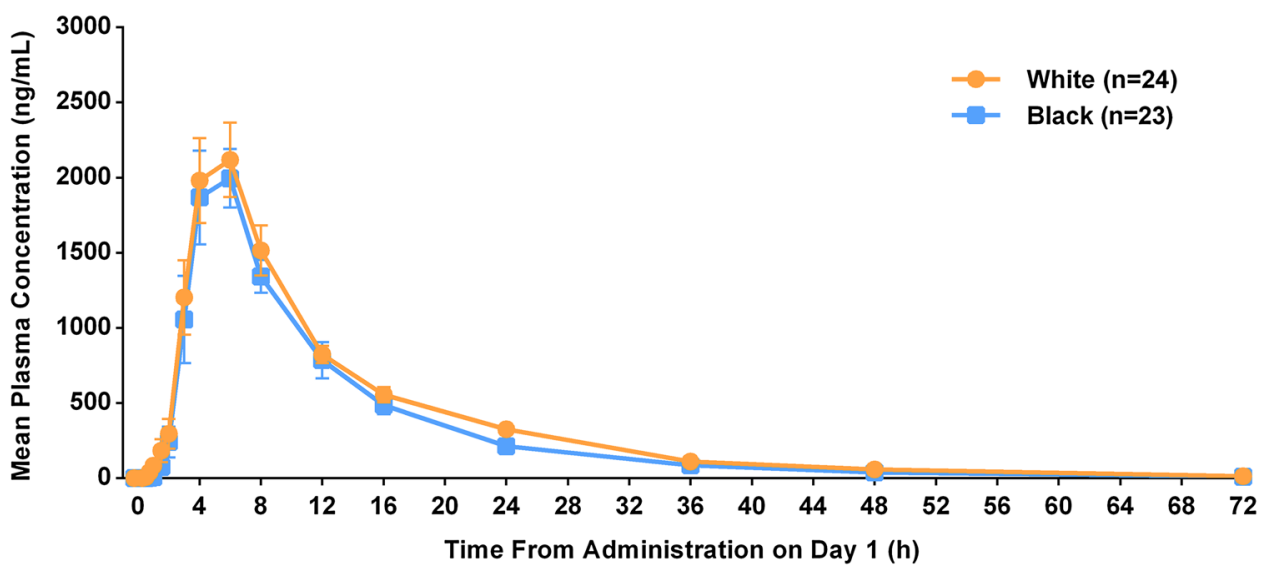

with elderly men, although individual $C_{\max }$ and AUC values for both elderly women and men overlapped.

\subsection{Safety and Tolerability}

The incidence and pattern of adverse events in subjects receiving AZL-M did not appear to be influenced by age, sex, or race (Table 4). The percentage of subjects reporting at least one adverse event was similar for AZL-M (32\%; $15 / 47$ subjects) and placebo (29 \%; 4/14 subjects). No subjects discontinued the study and no serious adverse events were reported. Headache was the most common adverse event (reported by four subjects [8.5\%] receiving AZL-M). Nausea, fatigue, blood pressure increase, 
Fig. 2 Azilsartan

concentration-time profiles after multiple dosing (Day 8) of azilsartan medoxomil according to age (top), sex (middle), and race (bottom). All data are mean \pm standard error of the mean
Azilsartan Exposure by Age: Elderly (65-85 yr) vs Young (18-45 yr)

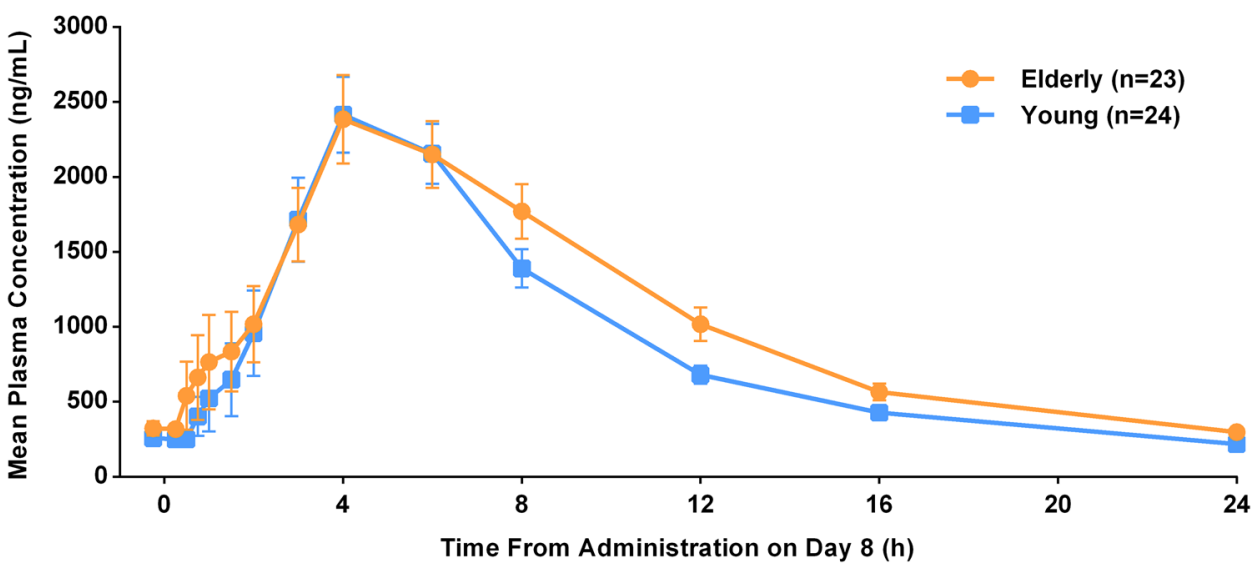

Azilsartan Exposure by Gender: Female vs Male

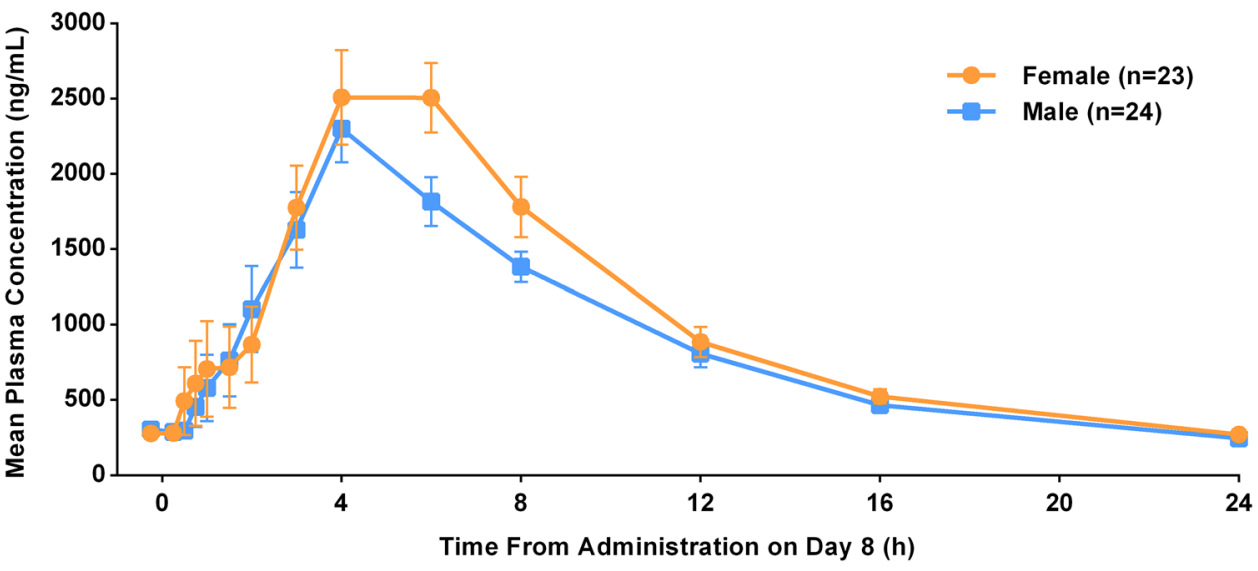

Azilsartan Exposure by Race: White vs Black

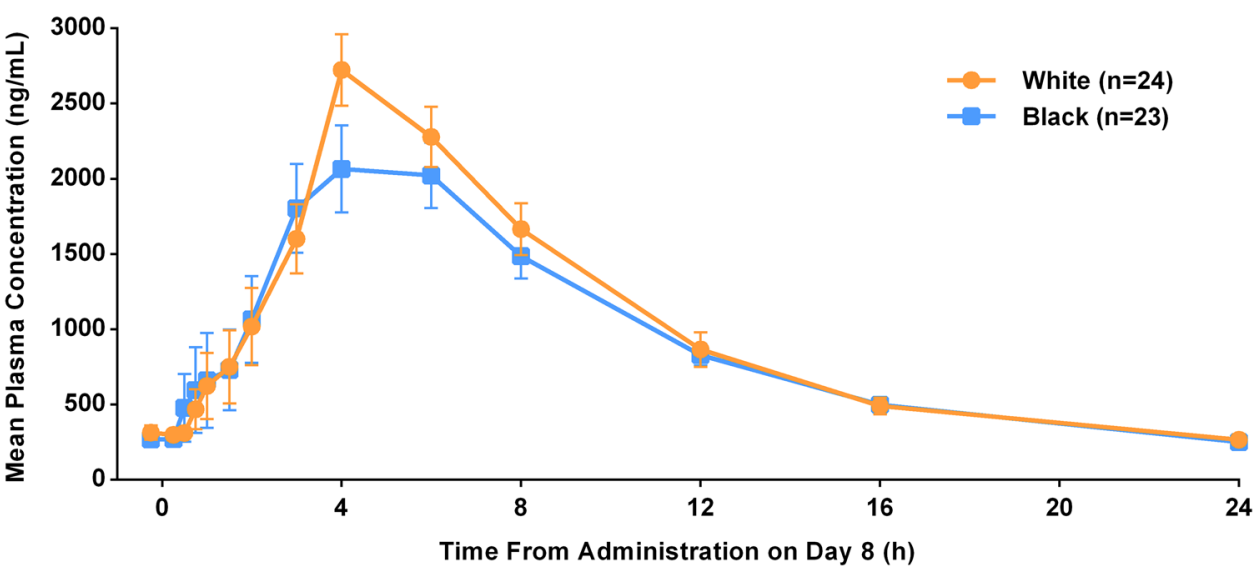

dizziness, and hot flush were each experienced by two subjects $(4.3 \%)$ receiving AZL-M. Treatment-emergent adverse events that were each reported by one subject were flatulence, vomiting, injection site hemorrhage, contusion, heart rate increase, decreased appetite, muscle spasms, and muscle tightness. Two subjects had abnormal laboratory values during the study (one AZL-M subject with abnormal alanine transaminase, aspartate aminotransferase, and $\gamma$ glutamyltransferase and one placebo subject with an abnormal creatine kinase value). No subject discontinued the study because of an abnormal laboratory value, and no abnormal laboratory value was considered a serious 
Table 2 Descriptive statistics for azilsartan plasma pharmacokinetic parameters according to age, sex, and race

\begin{tabular}{|c|c|c|}
\hline \multirow{2}{*}{$\begin{array}{l}\text { Parameter } \\
\text { Age }\end{array}$} & \multicolumn{2}{|c|}{ Arithmetic mean $\pm \mathrm{SD}$ or median [min, $\max ]$} \\
\hline & Elderly $(n=23)$ & Young $(n=24)$ \\
\hline \multicolumn{3}{|l|}{ Single dose (Day 1) } \\
\hline $\mathrm{AUC}_{0-\infty}(\mathrm{ng} \cdot \mathrm{h} / \mathrm{mL})$ & $26739 \pm 9027^{\mathrm{a}}$ & $21424 \pm 7221^{b}$ \\
\hline$C_{\max }(\mathrm{ng} / \mathrm{mL})$ & $3031 \pm 1110$ & $2520 \pm 1206$ \\
\hline$t_{\max }(\mathrm{h})$ & $6.0[3.0,12.0]$ & $5.0[3.0,24.0]$ \\
\hline$t_{1 / 2}(\mathrm{~h})$ & $12.17 \pm 1.94^{\mathrm{a}}$ & $10.64 \pm 1.47^{\mathrm{b}}$ \\
\hline \multicolumn{3}{|l|}{ Multiple dose (Day 8) } \\
\hline $\operatorname{AUC}_{0-24 \mathrm{~h}}(\mathrm{ng} \cdot \mathrm{h} / \mathrm{mL})$ & $25445 \pm 9563$ & $21502 \pm 7693$ \\
\hline$C_{\max }(\mathrm{ng} / \mathrm{mL})$ & $3253 \pm 1435$ & $3049 \pm 1319$ \\
\hline$t_{\max }(\mathrm{h})$ & $4.0[1.0,8.0]$ & $4.0[2.0,8.0]$ \\
\hline Sex & Female $(n=23)$ & Male $(n=24)$ \\
\hline \multicolumn{3}{|l|}{ Single dose (Day 1) } \\
\hline $\mathrm{AUC}_{0-\infty}(\mathrm{ng} \cdot \mathrm{h} / \mathrm{mL})$ & $25773 \pm 9525^{\mathrm{a}}$ & $22348 \pm 7195^{\mathrm{b}}$ \\
\hline$C_{\max }(\mathrm{ng} / \mathrm{mL})$ & $3023 \pm 1382$ & $2527 \pm 901$ \\
\hline$t_{\max }(\mathrm{h})$ & $6.0[3.0,12.0]$ & $4.0[3.0,24.0]$ \\
\hline$t_{1 / 2}(\mathrm{~h})$ & $11.40 \pm 1.37^{\mathrm{a}}$ & $11.38 \pm 2.27^{\mathrm{b}}$ \\
\hline \multicolumn{3}{|l|}{ Multiple dose (Day 8) } \\
\hline $\operatorname{AUC}_{0-24 \mathrm{~h}}(\mathrm{ng} \cdot \mathrm{h} / \mathrm{mL})$ & $25328 \pm 9313$ & $21614 \pm 8037$ \\
\hline$C_{\max }(\mathrm{ng} / \mathrm{mL})$ & $3536 \pm 1482$ & $2778 \pm 1156$ \\
\hline$t_{\max }(\mathrm{h})$ & $4.0[1.0,8.0]$ & $4.0[2.0,8.0]$ \\
\hline Race & White $(n=24)$ & Black $(n=23)$ \\
\hline \multicolumn{3}{|l|}{ Single dose (Day 1) } \\
\hline $\mathrm{AUC}_{0-\infty}(\mathrm{ng} \cdot \mathrm{h} / \mathrm{mL})$ & $25930 \pm 8827^{\mathrm{b}}$ & $22028 \pm 7840^{\mathrm{a}}$ \\
\hline$C_{\max }(\mathrm{ng} / \mathrm{mL})$ & $2816 \pm 1228$ & $2721 \pm 1146$ \\
\hline$t_{\max }(\mathrm{h})$ & $6.0[3.0,24.0]$ & $6.0[3.0,12.0]$ \\
\hline$t_{1 / 2}(\mathrm{~h})$ & $11.67 \pm 2.09^{\mathrm{b}}$ & $11.09 \pm 1.58^{\mathrm{a}}$ \\
\hline \multicolumn{3}{|l|}{ Multiple dose (Day 8) } \\
\hline $\mathrm{AUC}_{0-24 \mathrm{~h}}(\mathrm{ng} \cdot \mathrm{h} / \mathrm{mL})$ & $24320 \pm 8752$ & $22505 \pm 8932$ \\
\hline$C_{\max }(\mathrm{ng} / \mathrm{mL})$ & $3365 \pm 1053$ & $2924 \pm 1624$ \\
\hline$t_{\max }(\mathrm{h})$ & $4.0[2.0,8.0]$ & $4.0[1.0,8.0]$ \\
\hline
\end{tabular}

$t_{1 / 2}$ terminal half-life, $A U C_{0-24 h}$ area under the plasma concentration-time curve from time 0 to $24 \mathrm{~h}$ post dose, $A U C_{0-\infty}$ area under the plasma concentration-time curve from time $0 \mathrm{~h}$ to infinity, $C_{\max }$ maximum observed drug concentration in plasma, $t_{\max }$ time to reach $\mathrm{C}_{\max } S D$ standard deviation, min minimum, max maximum

a $n=22$

b $n=23$ adverse advent. There were no clinically important changes in 12-lead ECGs or physical examination findings.

Mean blood pressure tended to decrease over the study period in subjects receiving AZL-M. Transient systolic blood pressure measurements meeting the predefined criteria of very low $(<90 \mathrm{mmHg})$ were recorded for seven subjects $(15 \%)$ on AZL-M, but hypotension was not reported as an adverse event in any subject. An overall decrease in blood pressure was expected and is consistent with the clinical benefit of the drug. Of particular relevance to the aims of the current study, there was no evidence of a relationship of age, sex, or race with very low blood pressure measurements.

\section{Discussion}

In this single-center, single-blind, randomized, parallelgroup, single- and multiple-dose study, we investigated the impact of age, sex, and race on exposure to AZL (the active moiety of AZL-M) after administration of AZL-M $60 \mathrm{mg}$ (capsule formulation) once daily. Although AZL$M$ has been shown to decrease blood pressure in a dosedependent manner in a general population of subjects with mild-to-moderate hypertension [11-13], pharmacokinetic analyses such as the current study are important for determining the potential need for dosing adjustments in key subpopulations. We found that sex and race did 
Table 3 Statistical analysis of azilsartan plasma pharmacokinetic parameters according to age, sex, and race

\begin{tabular}{|c|c|c|c|}
\hline Parameter & LS mean & LS mean & Ratio $[90 \% \mathrm{CI}]$ \\
\hline Age & Elderly $(n=23)$ & Young $(n=24)$ & Elderly/young \\
\hline \multicolumn{4}{|l|}{ Single dose (Day 1) } \\
\hline $\mathrm{AUC}_{0-\infty}(\mathrm{ng} \cdot \mathrm{h} / \mathrm{mL})$ & $26,003^{\mathrm{a}}$ & $19,062^{\mathrm{b}}$ & $1.36[1.05,1.77]$ \\
\hline$C_{\max }(\mathrm{ng} / \mathrm{mL})$ & 2876 & 2093 & $1.37[1.02,1.86]$ \\
\hline \multicolumn{4}{|l|}{ Multiple dose (Day 8) } \\
\hline $\mathrm{AUC}_{0-24}(\mathrm{ng} \cdot \mathrm{h} / \mathrm{mL})$ & 24,375 & 19,384 & $1.26[1.01,1.57]$ \\
\hline$C_{\max }(\mathrm{ng} / \mathrm{mL})$ & 3036 & 2638 & $1.15[0.89,1.49]$ \\
\hline Sex & Female $(n=23)$ & Male $(n=24)$ & Female/male \\
\hline \multicolumn{4}{|l|}{ Single dose (Day 1) } \\
\hline $\mathrm{AUC}_{0-\infty}(\mathrm{ng} \cdot \mathrm{h} / \mathrm{mL})$ & $22,577^{\mathrm{a}}$ & $21,955^{\mathrm{b}}$ & $1.03[0.78,1.36]$ \\
\hline$C_{\max }(\mathrm{ng} / \mathrm{mL})$ & 2478 & 2430 & $1.02[0.75,1.39]$ \\
\hline \multicolumn{4}{|l|}{ Multiple dose (Day 8) } \\
\hline $\mathrm{AUC}_{0-24}(\mathrm{ng} \cdot \mathrm{h} / \mathrm{mL})$ & 22,565 & 20,938 & $1.08[0.86,1.36]$ \\
\hline$C_{\max }(\mathrm{ng} / \mathrm{mL})$ & 3049 & 2627 & $1.16[0.89,1.52]$ \\
\hline Race & White $(n=24)$ & Black $(n=23)$ & White/black \\
\hline \multicolumn{4}{|l|}{ Single dose (Day 1) } \\
\hline $\mathrm{AUC}_{0-\infty}(\mathrm{ng} \cdot \mathrm{h} / \mathrm{mL})$ & $24,599^{\mathrm{b}}$ & $20,150^{\mathrm{a}}$ & $1.22[0.95,1.58]$ \\
\hline$C_{\max }(\mathrm{ng} / \mathrm{mL})$ & 2547 & 2364 & $1.08[0.81,1.44]$ \\
\hline \multicolumn{4}{|l|}{ Multiple dose (Day 8) } \\
\hline $\mathrm{AUC}_{0-24}(\mathrm{ng} \cdot \mathrm{h} / \mathrm{mL})$ & 22,974 & 20,565 & $1.12[0.90,1.39]$ \\
\hline$C_{\max }(\mathrm{ng} / \mathrm{mL})$ & 3201 & 2502 & $1.28[0.99,1.65]$ \\
\hline
\end{tabular}

$C I$ confidence interval, $A U C_{0-24 h}$ area under the plasma concentration-time curve from time 0 to $24 \mathrm{~h}$ post dose, $A U C_{0-\infty}$ area under the plasma concentration-time curve from time $0 \mathrm{~h}$ to infinity, $C_{\max }$ maximum observed drug concentration in plasma

${ }^{\mathrm{a}} n=22$

${ }^{\mathrm{b}} n=23$ not have any clinically relevant influence on AZL exposure. Although a small increase in AZL exposure was seen in elderly vs. young subjects, the differences (36\% higher $\mathrm{AUC}_{0-\infty}$ [single dose], $26 \%$ higher $\mathrm{AUC}_{0-24}$ [multiple dose], and $37 \%$ higher single-dose $C_{\max }$ ) were not considered to be clinically relevant. Further subgroup analyses suggested higher AZL exposure in elderly women compared with young women, but the analysis was relatively underpowered and skewed by an outlier. Similarly, elderly women also had higher AZL exposure compared with elderly men, although there was overlap in individual values, suggesting no need for dose adjustments. These findings in subpopulations supplement other recently published pharmacokinetic data suggesting that there is also no clinically relevant effect of any degree of renal impairment (including end-stage renal disease) on AZL exposure after AZL-M administration [7]. The pharmacokinetic parameter estimates in the current analysis are broadly consistent with those reported in previous studies [2, 5, 7]. Mean elimination half-life was $10-12 \mathrm{~h}$ across the different subgroups and median $t_{\max }$ was $4.0 \mathrm{~h}$ after multiple dosing. We also confirmed that oral AZL-M administration displayed linear kinetics (ratio close to unity) and that the Day 8 multiple-dose measurements were carried out at steady state in the absence of any continuous AZL accumulation (no statistically significant difference between $C_{\min }$ values on Days 7 and 8) or any unexpected accumulation or reduction in exposure that might reflect time-dependent changes in AZL pharmacokinetics.

The ARBs are a recommended treatment option in elderly hypertensive patients, especially in those with CKD and proteinuria $[1,9,10]$. The current study provides reassuring pharmacokinetic data for AZL-M in this vulnerable population. This class of drugs is also a recommended treatment option in black hypertensive patients, especially in those with diabetes and/or kidney disease and especially in combination with either a diuretic or a calcium channel blocker (although it has been suggested that ARBs may be less effective in black patients when used as monotherapy) $[1,14,15]$. Preliminary results based on an analysis of three randomized controlled trials suggest that, at maximum approved doses, AZL-M lowers blood pressure more effectively in black patients with hypertension 


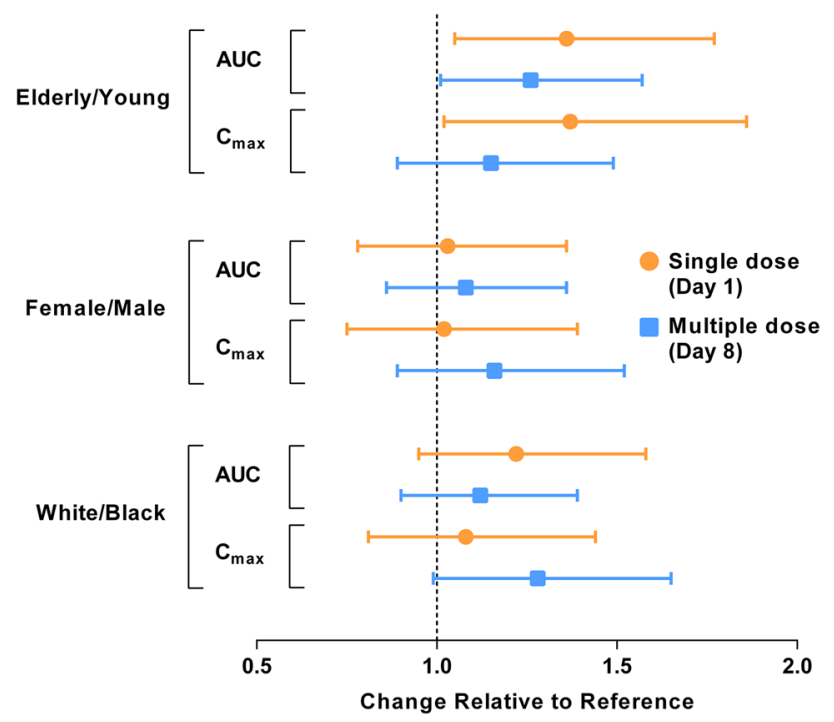

Fig. 3 Between-group ratios for AUC and $C_{\max }$ after a single dose (Day 1) and multiple dosing (Day 8). Data are ratios of the least squares means with associated $90 \%$ confidence intervals. $\mathrm{AUC}=\mathrm{AUC}_{0-\infty}$ for single dosing (Day 1) and $\mathrm{AUC}_{0-24}$ for multiple dosing (Day 8 ). The reference groups are young, male, and black. $C_{\max }$ maximum observed drug concentration in plasma, $A U C$ area under the plasma concentration-time curve, $A U C_{0-\infty}$ area under the plasma concentration-time curve from time $0 \mathrm{~h}$ to infinity, $\mathrm{AUC}_{0-24}$ area under the plasma concentration-time curve from time 0 to $24 \mathrm{~h}$ post dose

than the ARBs olmesartan or valsartan [16]. The current study complements this evidence by suggesting that AZL$M$ can be used effectively in black patients without the need for dose adjustment.

The current study also provided the opportunity to assess the safety and tolerability of AZL-M in these subpopulations. We found that AZL-M $60 \mathrm{mg}$ (capsule formulation) once daily was safe and well tolerated irrespective of age, sex, and race. It should be noted that the AZL-M capsule formulation used in the current study was switched to a once-daily tablet formulation $(20,40$, or $80 \mathrm{mg}$ ) during later-phase clinical development. Unlike the capsule formulation, the commercially available tablet is not affected by food and provides approximately $70 \%$ greater exposure to AZL compared with the capsule in the fasted state [6].

\section{Conclusion}

In this study, age, sex, and race had no clinically relevant influence on exposure to AZL (the active moiety of AZLM) during single and multiple dosing of AZL-M 60-mg capsules once daily in healthy volunteers. Similarly, age, sex, and race had no impact on AZL-M safety and tolerability. These results suggest that no AZL-M dose
Table 4 Adverse events reported by $\geq 2$ subjects in any group by age, sex, and race

\begin{tabular}{|c|c|c|c|c|}
\hline Preferred term ${ }^{\mathrm{a}}$ & AZL-M & Placebo & AZL-M & Placebo \\
\hline All subjects & $N=47$ & $N=14$ & - & - \\
\hline Any event & $15(31.9)$ & $4(28.6)$ & - & - \\
\hline Headache & $4(8.5)$ & 0 & - & - \\
\hline Dizziness & $2(4.3)$ & 0 & - & - \\
\hline Nausea & $2(4.3)$ & $2(14.3)$ & - & - \\
\hline Fatigue & $2(4.3)$ & 0 & - & - \\
\hline Hot flush & $2(4.3)$ & 0 & - & - \\
\hline BP increased & $2(4.3)$ & 0 & - & - \\
\hline \multirow[t]{2}{*}{ Age } & Young & & Elderly & \\
\hline & $N=24$ & $N=8$ & $N=23$ & $N=6$ \\
\hline Headache & $3(12.5)$ & 0 & $1(4.3)$ & 0 \\
\hline Dizziness & $2(8.3)$ & 0 & 0 & 0 \\
\hline Nausea & $2(8.3)$ & $2(25.0)$ & 0 & 0 \\
\hline Fatigue & $2(8.3)$ & 0 & 0 & 0 \\
\hline Hot flush & $2(8.3)$ & 0 & 0 & 0 \\
\hline BP increased & 0 & 0 & $2(8.7)$ & 0 \\
\hline \multirow[t]{2}{*}{ Sex } & Male & & Female & \\
\hline & $N=24$ & $N=8$ & $N=23$ & $N=6$ \\
\hline Headache & $1(4.2)$ & 0 & $3(13.0)$ & 0 \\
\hline Dizziness & 0 & 0 & $2(8.7)$ & 0 \\
\hline Nausea & $1(4.2)$ & $2(25.0)$ & $1(4.3)$ & 0 \\
\hline Fatigue & $2(8.3)$ & 0 & 0 & 0 \\
\hline Hot flush & $2(8.3)$ & 0 & 0 & 0 \\
\hline BP increased & $1(4.2)$ & 0 & $1(4.3)$ & 0 \\
\hline \multirow[t]{2}{*}{ Race } & White & & Black & \\
\hline & $N=24$ & $N=8$ & $N=23$ & $N=6$ \\
\hline Headache & $3(12.5)$ & 0 & $1(4.3)$ & 0 \\
\hline Dizziness & $2(8.3)$ & 0 & 0 & 0 \\
\hline Nausea & $2(8.3)$ & $1(12.5)$ & 0 & $1(16.7)$ \\
\hline Fatigue & $2(8.3)$ & 0 & 0 & 0 \\
\hline Hot flush & $2(8.3)$ & 0 & 0 & 0 \\
\hline BP increased & $1(4.2)$ & 0 & $1(4.3)$ & 0 \\
\hline
\end{tabular}

Data are presented as $n(\%)$

AZL-M azilsartan medoxomil, $B P$ blood pressure

a A subject who reported $\geq 2$ adverse events within the same preferred term was counted only once for that term

adjustments are required based on age, sex, or race (black or white).

Acknowledgments/disclosures This study was sponsored by Takeda Development Center Americas, Deerfield, IL, USA. The sponsor designed the study. Dr. Robert Harrell, the primary investigator, conducted the study and collected the data. The sponsor and the authors analyzed and interpreted the data. The sponsor wrote the study report. The authors and the sponsor agreed jointly to submit the manuscript for publication. The authors drafted the manuscript with medical writing assistance provided by Absolute Healthcare 
Communications Ltd, Twickenham, UK, and received no financial support for its development. The authors thank the staff of Covance Laboratories, Madison, WI, USA, for conducting the bioanalytical portion of the study. Caroline Dudkowski and Wencan Zhang are employees of Takeda. Aziz Karim is a former employee of Takeda and held stock options. Robert Harrell is a phase I clinical trial investigator at Arkansas Research Medical Testing LLC (Little Rock, AK, USA), the company sponsored by Takeda to perform the study, and has no other potential conflicts of interests. Preliminary results from this study were presented at the 2012 American Society for Clinical Pharmacology and Therapeutics (ASCPT) Annual Meeting; March 12-17, 2012; National Harbor, MD, USA.

\section{References}

1. James PA, Oparil S, Carter BL, et al. 2014 evidence-based guideline for the management of high blood pressure in adults: report from the panel members appointed to the Eighth Joint National Committee (JNC 8). JAMA. 2014;311:507-20.

2. Zaiken K, Cheng JW. Azilsartan medoxomil: a new angiotensin receptor blocker. Clin Ther. 2011;33:1577-89.

3. Edarbi (azilsartan medoxomil) tablets [U.S. prescribing information]. Arbor Pharmaceuticals, LLC, Atlanta, GA, USA. July 2014. http://www.accessdata.fda.gov/drugsatfda_docs/label/ 2014/200796s006lbl.pdf. Accessed 9 Jan 2015.

4. Edarbi (azilsartan medoxomil) tablets [summary of product characteristics]. Takeda Pharma A/S, Taastrup, Denmark. Oct 2014. http://www.ema.europa.eu/docs/en_GB/document_library/ EPAR_-_Product_Information/human/002293/WC500119204. pdf. Accessed 9 Jan 2015.

5. Perry C. Azilsartan medoxomil: a review of its use in hypertension. Clin Drug Investig. 2012;32:621-39.

6. U.S. Food and Drug Administration, Center for Drug Evaluation and Research. Azilsartan medoxomil (Edarbi) NDA 200-796 Clinical Pharmacology and Biopharmaceutics Review, February 25, 2011. http://www.accessdata.fda.gov/drugsatfda_docs/nda/ 2011/200796Orig1s000ClinPharmR.pdf. Accessed 9 Jan 2015.

7. Preston RA, Karim A, Dudkowski C, Zhao Z, Garg D, Lenz O, Sica DA. Single-center evaluation of the single-dose pharmacokinetics of the angiotensin II receptor antagonist azilsartan medoxomil in renal impairment. Clin Pharmacokinet. 2013;52:347-58.

8. Preston R, Karim A, Garg D, Zhao Z, Dudkowski C. Singlecenter phase I study of the single- and multiple-dose pharmacokinetics and safety of azilsartan medoxomil (AZL-M) in hepatic impairment [abstract no. PII-99]. Clin Pharmacol Ther. 2012;91(Suppl 1):S89.

9. Pimenta E, Oparil S. Management of hypertension in the elderly. Nat Rev Cardiol. 2012;9:286-96.

10. Aronow WS, Fleg JL, Pepine CJ, et al. ACCF/AHA 2011 expert consensus document on hypertension in the elderly: a report of the American College of Cardiology Foundation Task Force on Clinical Expert Consensus Documents developed in collaboration with the American Academy of Neurology, American Geriatrics Society, American Society for Preventive Cardiology, American Society of Hypertension, American Society of Nephrology, Association of Black Cardiologists, and European Society of Hypertension. J Am Soc Hypertens. 2011;5:259-352.

11. Bakris GL, Sica D, Weber M, et al. The comparative effects of azilsartan medoxomil and olmesartan on ambulatory and clinic blood pressure. J Clin Hypertens (Greenwich). 2011;13(2):81-8.

12. Sica D, White WB, Weber MA, et al. Comparison of the novel angiotensin II receptor blocker azilsartan medoxomil vs valsartan by ambulatory blood pressure monitoring. J Clin Hypertens (Greenwich). 2011;13(7):467-72.

13. White WB, Weber MA, Sica D, Bakris GL, Perez A, Cao C, Kupfer S. Effects of the angiotensin receptor blocker azilsartan medoxomil versus olmesartan and valsartan on ambulatory and clinic blood pressure in patients with stages 1 and 2 hypertension. Hypertension. 2011;57:413-20.

14. Flack JM, Nasser SA, Levy PD. Therapy of hypertension in African Americans. Am J Cardiovasc Drugs. 2011;11:83-92.

15. Flack JM, Sica DA, Bakris G, et al. Management of high blood pressure in blacks: an update of the International Society on Hypertension in Blacks consensus statement. Hypertension. 2010;56:780-800.

16. White WB, Weber MA, Bakris GL, Song E, Handley A, Kupfer S. Effects of azilsartan medoxomil vs olmesartan, valsartan on ambulatory and clinic BP in hypertensive black patients [abstract]. J Clin Hypertens. 2012;14(Suppl 1):11. 